\title{
Effect of photo-thermal acceleration on in-office bleaching
}

\author{
Feng $\mathrm{Qi}^{1} \cdot$ Masayuki Otsuki $^{1} \oplus \cdot$ Noriko Hiraishi $^{1} \cdot$ Takashi Hatayama $^{1} \cdot$ Chamari Lasindra Wijethunge $^{1} \cdot$ Junji Tagami $^{1}$
}

Received: 1 November 2020 / Accepted: 26 March 2021 / Published online: 15 May 2021

(C) The Author(s) 2021

\begin{abstract}
The purpose is to evaluate the effect of photo-thermal acceleration on in-office bleaching efficiency using a bleaching agent without photocatalysts in vitro. Artificially discolored bovine lower incisors were prepared, and the mixed in-office bleaching material contained hydrogen peroxide $23 \%$ was applied by following treatment for $10 \mathrm{~min}$ : high-(HI group) and low-intensity LED lights (LI group), oven at $38^{\circ} \mathrm{C}\left(\mathrm{OV}\right.$ group), and room temperature at $23{ }^{\circ} \mathrm{C}$ (RT group). Color was measured before and after bleaching and color difference $\left(\Delta E^{*}\right)$ was calculated. The data were statistically analyzed using a two-way ANOVA and Tukey's post hoc test. The temperature change $(\Delta T)$ of applied bleaching agent in HI and LI groups was measured using a thermography and was analyzed using a $\mathrm{T}$ test. The bleaching procedures were repeated 6 times. Irradiation in the HI group resulted in the highest $\Delta E$, followed by the LI group whose $\Delta E$ was significantly lower. Both irradiated modes exhibited higher $\Delta E$ compared to non-irradiated $\mathrm{OV}$ and RT groups which were not significantly different from each other. The average temperature rise of bleaching agents in $\mathrm{HI}$ and LI groups after $10 \mathrm{~min}$ irradiation was $15.00{ }^{\circ} \mathrm{C}$ and $11.80{ }^{\circ} \mathrm{C}$, respectively. The effect of photo-thermal acceleration was proved for an in-office bleaching agent without photocatalysts in vitro.
\end{abstract}

Keywords Tooth bleaching $\cdot$ Photo irradiation $\cdot$ Temperature $\cdot$ Hydrogen peroxide $\cdot$ Tooth color

\section{Introduction}

Tooth bleaching is one of the most popular and conservative dental procedures to lighten discolored teeth, which can be accomplished in-office, at-home, or dentist-supervised nightguard bleaching and bleaching with over-the-counter (OTC) products[1, 2]. For in-office bleaching, high concentration

\section{Masayuki Otsuki \\ otsuki.ope@tmd.ac.jp \\ Feng Qi \\ qi.ope@tmd.ac.jp \\ Noriko Hiraishi \\ hiraope@tmd.ac.jp \\ Takashi Hatayama \\ 060371@gmail.com}

Chamari Lasindra Wijethunge

clwijethunge@gmail.com

Junji Tagami

tagami.ope@tmd.ac.jp

1 Cariology and Operative Dentistry, Graduate School of Medical and Dental Sciences, Tokyo Medical and Dental University, 1-5-45 Yushima, Bunkyo-ku, Tokyo 113-8549, Japan hydrogen peroxide $(25-38 \%)$ is usually chosen because of the advantages of reduced total treatment time [3] and greater potential for immediate results that may enhance patient satisfaction and motivation, and the exposure of soft tissue is also avoided due to dentist's control [4]. Therefore, compared to the other two bleaching methods, the in-office bleaching technique which combines with the use of light sources is appreciated by the patient to obtain faster results $[5,6]$.

The bleaching mechanism is described as the process that hydrogen peroxide decomposes to produce free radicals which react with chromogens composed of pigmented dual-bond compounds and/or metallic compounds [7-9]. This kind of chromogen accumulates in the tooth (intrinsic) or on the tooth (extrinsic) [9]. After reacting, the colorless molecular structures are generated resulting in tooth bleaching [10]. Meanwhile, many influence factors such as the temperature, light, or energy sources, photocatalyst, $\mathrm{pH}$, the concentration of hydrogen peroxide, and the number of bleaching times affect the bleaching effect $[11,12]$.

The theoretical advantages of the light sources are to increase the chemical reaction rate of the bleaching process by producing heat [13] or to enhance the bleaching efficacy of bleaching materials by light activation of photocatalysts $[14,15]$ and 
consequently, to reduce the duration of the bleaching session. Suyama et al. [16] concluded that hydrogen peroxide-based bleaching agent containing titanium oxide photocatalyst exhibited a higher bleaching effect on account of light absorption. These photocatalysts reacted with the light at a very specific wavelength and transferred a small fraction of the light energy to the peroxide gel to activate bleaching procedures [14]. In addition to photocatalysts, higher bleaching effects were also induced by a higher increase in temperature caused by irradiation from high-intensity lights or lasers $[17,18]$. Some specific colorants which give bleaching materials a colored appearance such as carotene also increase the heat conversion owing to the absorption of light is easier[16, 19]. Accordingly, a lot of research has utilized light sources with various wavelengths and power intensity such as plasma arc, lasers, quartz tungsten halogen lights, and light-emitting diodes (LED) to increase the bleaching efficacy of in-office bleaching materials with photocatalysts or photoactive colorants [17, 18, 20].

Some light sources, like LED lights that are specifically designed for bleaching procedures, have different modes illuminated for discolored teeth. Moreover, different modes generally have various wavelengths and different power intensities, thereby producing potentially different thermal emissions in the bleaching process [21, 22]. Usumez et al. [23] reported that the temperature rise was less by LED light irradiation during the polymerization of resin cement. Similar results regarding the temperature rise were obtained when LED was used in the bleaching process [16]. However, the relationship between the bleaching effect and temperature rises of bleaching material without photocatalysts or colorants caused by different power intensities LED lights was not clear. There is only limited information offered by the literature. Therefore, it should be investigated further by assessing the risks/benefits of LED lights, avoiding pulp damage caused by excessive heating in pursuit of high bleaching efficiency, and providing information to meet the need of seeking suitable light irradiation.

Therefore, the purpose of this study was to evaluate the effect of photo-thermal acceleration on in-office bleaching efficiency using a bleaching agent without photocatalysts in vitro.

Null hypothesis: (1) The in-office bleaching efficiency is not affected by temperature rise induced by light activation. (2) There is no difference in the temperature rise between the light groups.

\section{Materials and methods}

\section{Artificially discolored bovine tooth models}

\section{Specimen preparation}

Specimens were prepared according to the method of previous literature [11, 24]. Extracted frozen bovine teeth were defrosted with running tap water at room temperature before the experiment. After carefully removing soft-tissue remnants attached to the teeth by a scalpel, labial enamel surfaces were polished using silicon carbide papers from \#600- to \#800-grit (Sankyorikagaku, Saitama, Japan) under water cooling until almost $1 \mathrm{~mm}$ enamel in thickness was left to obtain flat standardized enamel surface. Then, two enamel-dentin specimens of approximately $5 \times 5 \mathrm{~mm}$ in size were obtained from one tooth by rotary diamond saw (Mini Lab-cutter MC-110, Maruto instrument, Tokyo, Japan). The pulpal dentin of each specimen was covered with dental wax (Utility wax, GC, Tokyo, Japan), and the specimen was embedded in a cylindrical acrylic tube with $7 \mathrm{~mm}$ in height and $10 \mathrm{~mm}$ in internal diameter by polymerization of dental self-curing acrylic resin (Unifast III, GC, Tokyo, Japan). After dental wax was removed, the dentin surface was irrigated with the $5 \%$ sodium hypochlorite solution (Wako pure chemical, Osaka, Japan) for $30 \mathrm{~s}$ to remove organic tissue remnants followed by complete washing, drying, and finally etching with $40 \%$ phosphoric acid (K-etchant gel, Kuraray Noritake Dental, Tokyo, Japan) for $10 \mathrm{~s}$, to encourage stain uptake into the tubule system. Then, specimens were polished again with \#1,000and \#1,200-grit silicon carbide paper to get a smooth and flat enamel surface.

\section{Artificial staining}

The specimens were immersed in the black tea solution extracted by putting two tea bags (Lipton yellow label tea bags, Uniliver Japan, Tokyo, Japan) in $50 \mathrm{ml}$ boiling water for $5 \mathrm{~min}$ and then stored in an incubator for 7 days at $37^{\circ} \mathrm{C}$. The solution was stirred once every day to avoid the precipitation of the solution and changed on the fourth day.

Stained labial surface color was recorded by CIE $L^{*} a^{*} b$ value with a colorimeter (Color-checker NR-11, Nippon Denshoku, Tokyo, Japan) after washing and drying for each specimen. Each color measurement was done three times and the average of three measurements was taken as the measured value. The specimens in which $L^{*}$ value showed between 50 and 65 were selected for the following experiment and randomly assigned into four groups of 12 specimens $(n=12)$ each to complete the bleaching process. Baseline $L^{*}, \mathrm{a}^{*}$, and $b^{*}$ values were applied, and enamel surface images were captured with a digital camera.

\section{Tooth bleaching procedure}

The components of bleaching material used in the present study are listed in Table 1 . Whiteessence whitening Pro consists of a liquid with $35 \% \mathrm{H}_{2} \mathrm{O}_{2}$ and a viscous gel 
Table 1 Bleaching material used in this study

\begin{tabular}{ll}
\hline Product (manufacture) & Composition \\
\hline Whiteessence whitening Pro, (White Essence, Tokyo, Japan) & Syringe \\
& Thickener \\
& Sodium hydrogen carbonate \\
& Purified water \\
& Liquid \\
& $35 \%$ hydrogen peroxide
\end{tabular}

which contains thickener and sodium hydrogen carbonate. After mixing for $60 \mathrm{~s}$, the concentration of $\mathrm{H}_{2} \mathrm{O}_{2}$ becomes 23\%. Mixed in-office bleaching material (Whiteessence whitening Pro, White Essence, Tokyo, Japan) was applied on the enamel surface according to the manufacturer's instruction and the applied surface was treated by following procedures for $10 \mathrm{~min}$ for all groups:

HI group Blue LED (WE light Class II, White Essence, Tokyo, Japan) was irradiated using "High" intensity mode with power density $55 \mathrm{~mW} / \mathrm{cm}^{2}$.

LI group The same light was irradiated using "Low" intensity mode with power density of $45 \mathrm{~mW} / \mathrm{cm}^{2}$.

OV group Specimens were placed in an oven at $38{ }^{\circ} \mathrm{C}$ without light irradiation.

$R T$ group Specimens were left in darkness at room temperature $23^{\circ} \mathrm{C}$.

WE light Class II can be used to illuminate multiple teeth at the same time, and the distance between the blue LED and the specimen surface was fixed in $5 \mathrm{~mm}$ (Fig. 1). After 10 min application, the bleaching material was removed with damp cotton, and color measurements and photographs were performed again. The bleaching procedure and color measurements were repeated 6 times. Thus, the total time of bleaching was $60 \mathrm{~min}$.

The color differences in $\Delta E^{*}$ values obtained from $L^{*}$, $a^{*}$, and $b^{*}$ value at the baseline and after each bleaching application period were expressed by the formula:

$\Delta E=\left((\Delta L *)^{2}+(\Delta a *)^{2}+(\Delta b *)^{2}\right)^{1 / 2}$

$\Delta L^{*}, \Delta a^{*}$, and $\Delta b^{*}$ represent the difference of $L^{*}$ values, $a^{*}$ values, and $b^{*}$ values between baseline and after bleaching respectively.

\section{Temperature measurement}

Temperature measurement was carried out under controlled temperature $\left(23^{\circ} \mathrm{C}\right)$ condition using the air condition. In HI and LI groups, temperature change in $\Delta T$ of applied bleaching material was measured before and after light irradiation using a thermography (FLIR C2, FLIR System AB, Sweden). This is the first pocket-sized multifunction infrared thermography in the world, measuring a temperature range

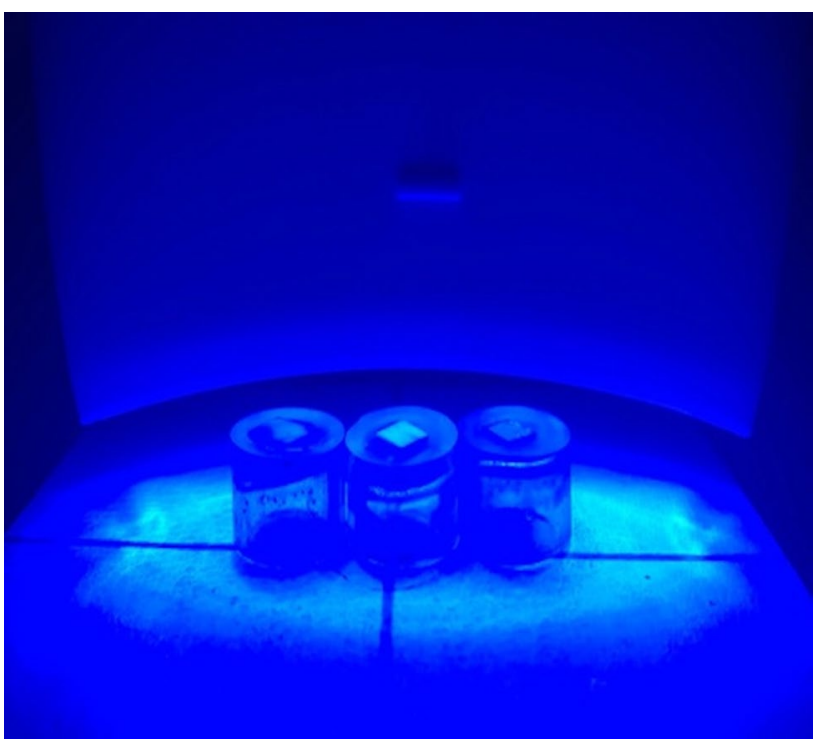

Fig. 1 The multiple teeth covered with bleaching material were illuminated for $10 \mathrm{~min}$ at $5 \mathrm{~mm}$ from the LED

Table 2 Mean of temperature change $(\Delta T)$ at each bleaching step in $\mathrm{HI}$ and LI group

\begin{tabular}{lll}
\hline Bleaching time & HI group & LI group \\
\hline 1 & $14.80(0.29)$ & $11.60(0.70)$ \\
2 & $15.00(0.27)$ & $11.70(0.45)$ \\
3 & $15.10(0.32)$ & $11.80(0.47)$ \\
4 & $15.10(0.25)$ & $11.80(0.25)$ \\
5 & $15.10(0.19)$ & $12.00(0.30)$ \\
6 & $14.90(0.31)$ & $12.10(0.21)$ \\
Mean (SD) & $15.00(0.27)$ & $11.80(0.40)$ \\
\hline
\end{tabular}

from $-10{ }^{\circ} \mathrm{C}$ to $150{ }^{\circ} \mathrm{C}$. The mean of temperature change $(\Delta T)$ at each bleaching step in the light irradiation groups is listed in Table 2.

\section{Statistical analysis}

The assumption of normal distribution was tested using the Kolmogorov-Smirnov test. The color difference $\left(\Delta E^{*}\right)$ was statistically analyzed using a two-way ANOVA and Tukey's 


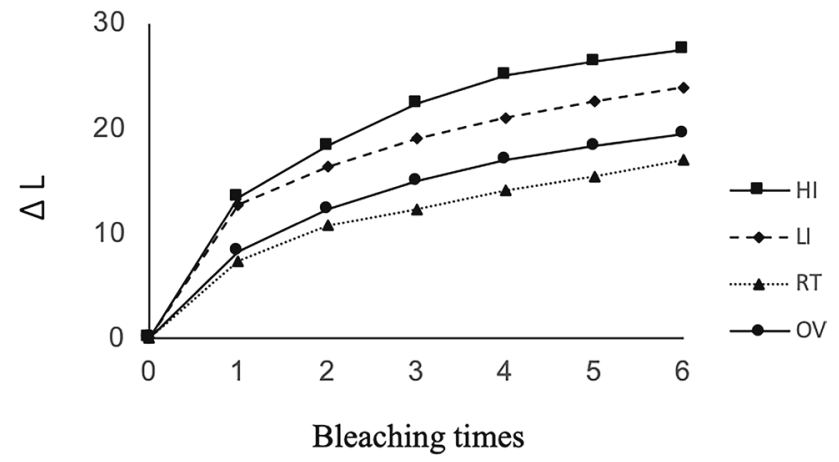

Fig. 2 Mean of $\Delta L^{*}$ at each bleaching step in all groups

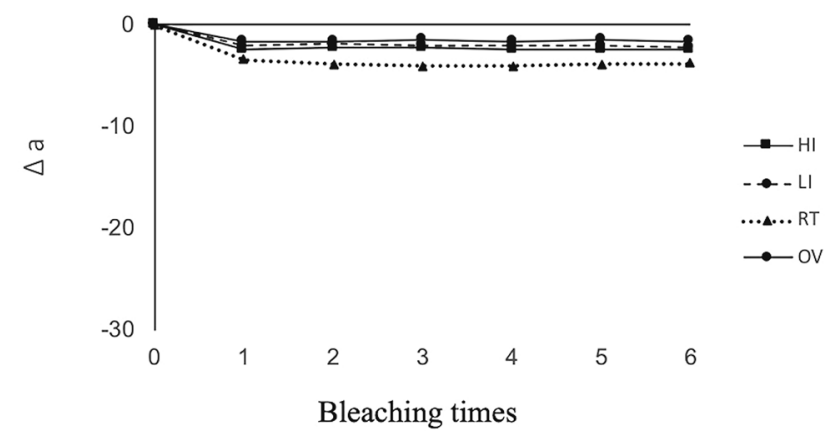

Fig. 3 Mean of $\Delta a^{*}$ at each bleaching step in all groups

post hoc test (significance level 0.05 ) and a $T$ test was used to identify differences in temperature change $(\Delta T)$.

\section{Results}

The mean of $\Delta L^{*}, \Delta a^{*}, \Delta b^{*}$, and the color difference values $\left(\Delta E^{*}\right)$ at each bleaching step in all groups are displayed in Figs. 2, 3, 4 and 5, respectively. A positive bleaching effect in typical images of specimens is visually found in Fig. 6 . $\Delta L^{*}$ values gradually increased indicating the increase in brightness and $\Delta b^{*}$ values showed a decrease in all groups due to the blue transition of hue. However, the value of $\Delta a^{*}$ was little changed even after repeated bleaching in each group, indicating that it had little effect on the red-green change of teeth.

Color difference $\Delta E^{*}$ values gradually increased with repeated bleaching in all groups. LED light in the highintensity mode resulted in the highest $\Delta E^{*}$ (from 19.04 for the first time bleaching to 31.86 for the sixth time bleaching), followed by low-intensity mode of the same light source whose $\Delta E^{*}$ (from 17.89 to 28.47 ) was significantly lower $(P<0.05)$. Both light irradiation modes exhibited higher $\Delta E^{*}$ compared to non-irradiated $\mathrm{OV}$ and RT groups $(P<0.05)$ which were not significantly different from each other $(P>0.05)$.

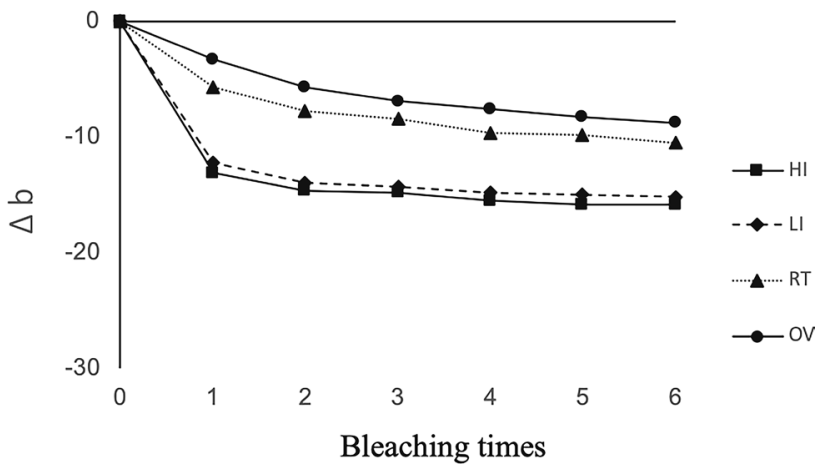

Fig. 4 Mean of $\Delta b^{*}$ at each bleaching step in all groups

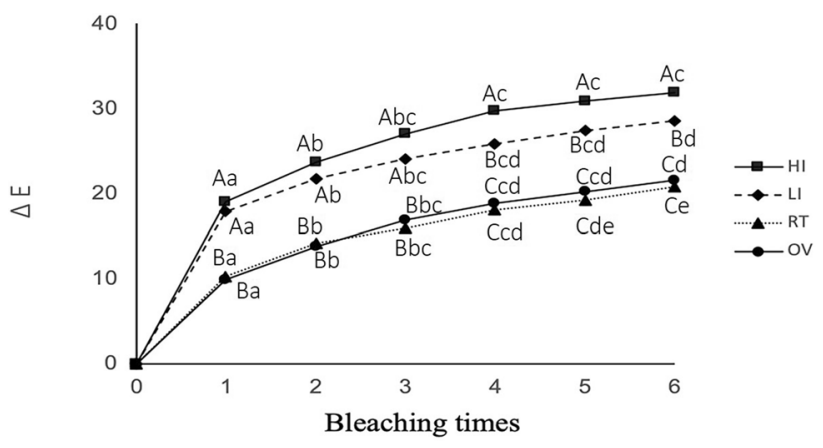

Fig. 5 Mean of color difference values $\left(\Delta E^{*}\right)$ at each bleaching step in all groups. Different uppercase letters represent the statistical differences between groups and different lowercase letters represent the statistical difference between application times $(P<0.05)$.

Two-way ANOVA showed that the number of bleaching agent application times and groups significantly affected $\Delta E$. There was a significant interaction between the number of bleaching agent application times and the groups $(P<0.001)$.

According to the temperature measurement using the thermography, the temperature change in light irradiation groups was calculated. The mean of temperature change $(\Delta T)$ at each bleaching step in the light irradiation groups is listed in Table 2. The temperature rise of bleaching agent in $\mathrm{HI}$ and LI groups after $10 \mathrm{~min}$ irradiation of each bleaching time was $15.00 \pm 0.27^{\circ} \mathrm{C}$ and $11.80 \pm 0.40{ }^{\circ} \mathrm{C}($ mean $\pm \mathrm{SD})$ respectively. HI group showed significant $(P<0.05)$ higher temperature rise in the bleaching process compared with the LI group (Fig. 7).

\section{Discussion}

The efficacy of different light sources in the bleaching process has been extensively studied by many researchers. When the light is irradiated onto a bleaching product, respective photons are absorbed by bleaching agents, and its 
Fig. 6 Typical color change in bovine teeth specimens of all groups at each bleaching step

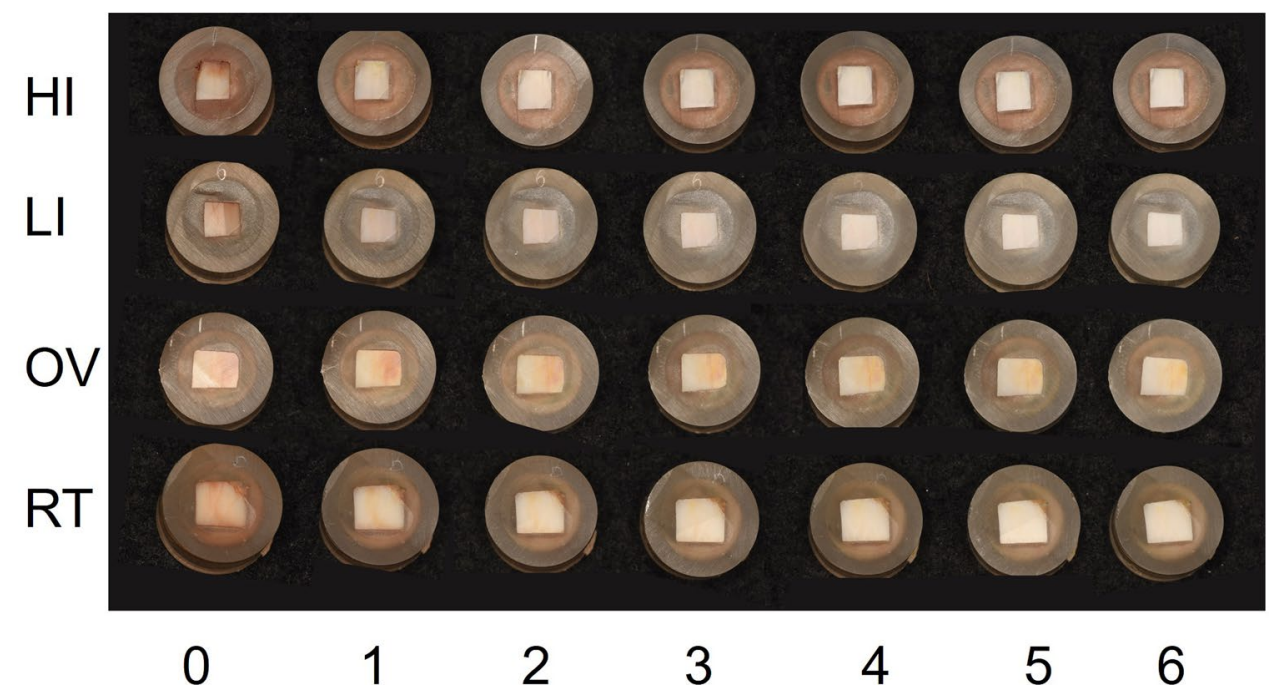

$\left({ }^{\circ} \mathrm{C}\right)$

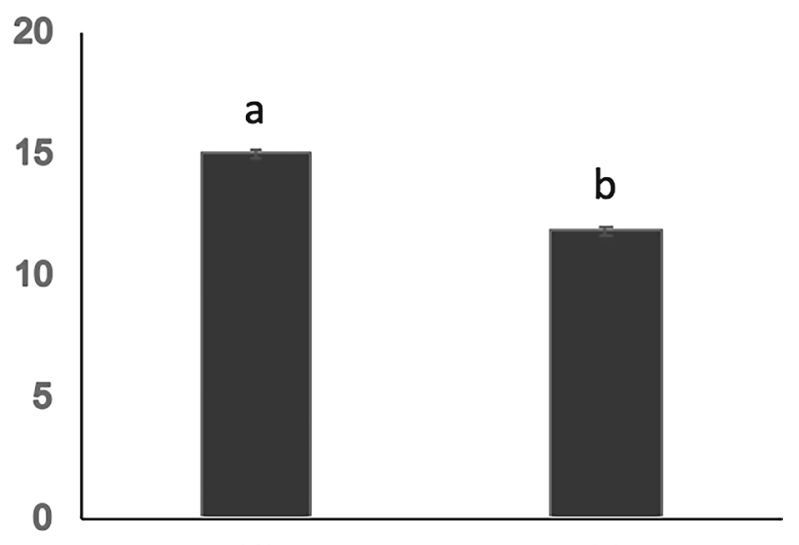

$\mathrm{HI}$

\section{Bleaching groups}

Fig. 7 The average temperature change $(\Delta T)$ of bleaching agent in $\mathrm{HI}$ and LI group after $10 \mathrm{~min}$ irradiation. Different lowercase letters represented significant differences between groups $(P<0.05)$.

energy is converted into heat, which is the important factor for a temperature rise $[18,25,26]$. Then, redox reaction rate might be accelerated by rising temperature according to the molecular collision theory, and the likelihood of bonding cleavages and reactions is increasing due to molecules move faster and collisions among them become frequent [27]. In addition to it, more hydroxyl radicals that react with the organic molecules are produced from hydrogen peroxide when the temperature rises. It is known that a $10{ }^{\circ} \mathrm{C}$ increase in temperature doubles the production of hydroxyl radical [28]. As a result, many high-intensity light sources are used to increase the temperature of the bleaching material, thus enhancing the bleaching effect of hydrogen peroxide.
However, some previous studies showed that the efficacy of light irradiation for bleaching materials was not obvious $[29,30]$. The present study investigated the effects of the heating mechanism on tooth bleaching using blue light LED as, compared to heating without light, the use of bleaching material without photocatalysts eliminated the influence of light absorption by activating photocatalysts.

In vitro samples used in this method were stained in advance by black tea to simulate clinically discolored teeth. This approach has also been shown in many studies [11, 24]. As the most extensively used substitute for human teeth, bovine teeth eliminate the factors of insufficient quantity and bad quality because of different characteristics of human teeth like the degree of staining, mineralization status, or lesions which may cause a high deviation in the experimental results $[31,32]$. Besides, it was reported that human and bovine teeth both exhibit similar physicochemical properties in hard tissues [33, 34]. Organic substances found in coffee, tea, and even wine are known to cause discolor on teeth. The stain made by black tea which is the typical extrinsic chromogens was easy to standardize, reproduce, and control [11] to simulate the discolor of teeth in vivo before the bleaching treatment.

In-office bleaching materials with neutral/alkaline $\mathrm{pH}$ are less aggressive to the enamel surface compared with acidic $\mathrm{pH}$ bleaching materials and maintain the $\mathrm{pH}$ during the application, allowing them to be left on the enamel surface for the whole application period [35]. In the present study, the bleaching material with a $\mathrm{pH}$ value of approximately 7.3 showed a greater bleaching effect. A dental colorimeter was used to measure the color change of teeth. $\Delta \mathrm{E}$ value which was more than 3.3 was considered as a difference of color in the dental crown $[14,16,36]$. Compared with visual analysis, colorimeter breaks an overall color value into $L^{*}, a^{*}$, and $b^{*}$ components, and provides more efficient measurement in tooth color to make statistical analysis precise [37]. 
Our results suggested the higher the temperature rise when exposed to the visible light, the better the bleaching efficiency was obtained even without the presence of photocatalysts. The best bleaching effect occurred in the HI group, which produced a temperature rise of approximately $3{ }^{\circ} \mathrm{C}$ higher compared to the LI group. $\Delta E^{*}$ also showed significantly higher in the irradiation group (HI and LI group) than the RT group which without any heat treatment. Therefore, the first null hypothesis that in-office bleaching efficiency is not affected by temperature rise induced by light activation was rejected. This finding agreed with the previous studies that high-intensity light produced more heat and had a positive effect on bleaching efficiency $[14,18,19]$.

In the pilot study, the temperature of the bleaching agent reached $38{ }^{\circ} \mathrm{C}$ after $10 \mathrm{~min}$ high-intensity light irradiation. To compare the effect of the heat, the temperature in the $\mathrm{OV}$ group was set at $38^{\circ} \mathrm{C}$ to achieve heat control. The use of an oven has not been found in the previous literature in tooth bleaching experiments; while it is difficult to interpret the result that a statistically significant difference was found between the light irradiation groups and the OV group. Although the potential roles of the oven in our study were to produce heat, it may happen that the heat generated by the oven reached the surface of the bleaching material through the air, making the temperature rise which was not high enough to affect the outcome of the bleaching procedure. However, compared with the heat produced by light irradiation, which was mostly concentrated in bleaching materials, the heat loss in the air might be relatively less. The dynamics of temperature change of bleaching materials might affect the bleaching effect in this study.

On the other hand, it could be thought that light itself may accelerate the reaction of hydrogen peroxide in the bleaching material. The peak wavelength of LED light in this study was $460 \mathrm{~nm}$ within the blue range, which indicated that it was more easily absorbed by the bleaching material due to higher scattering and penetrating [28]. As a result, more free reactive oxygen species might be produced from bleaching materials by visible-light irradiation. Moreover, De Moor et al. [38] reported that laser light can have several photochemical processes like photo-thermal effects (heat emission) or photooxidation (photobleaching) triggered by light absorption. These photochemical processes such as heat emission and photodynamic effects may also occur in LED lights, providing a greater effect on bleaching efficiency. Another factor that contributed to this result could be the photoreception of the pigment molecules in the dental surface. Because of the wavelength peak of light closed to the absorption peak of the molecules, light activation of the molecules made them breakdown into the smaller compound. The violet light LED has been proven to coincide with the absorption peak of pigmented molecules [10]. Further studies are necessary to evaluate the actual effect of the blue light LED on dental pigment molecules except for the effect of the light on the bleaching agent.

Although LED lights are proven to be effective in activating hydrogen peroxide, the adverse effects of heat production cannot be ignored. It was shown that a longer period of treatment not only speeded up penetration of peroxide into the pulp but also increased the temperature in intra-pulpal, sometimes caused irreversible damage so that limited clinical use [39]. For our in vitro study, the initial temperature of the bleaching material was $23{ }^{\circ} \mathrm{C}$. In the light irradiation groups, the average temperature increase of the bleaching agent after 10 min irradiation was $15.00{ }^{\circ} \mathrm{C}$ in the high-intensity mode and $11.80{ }^{\circ} \mathrm{C}$ in the low-intensity mode to reach the final temperature of $38.00{ }^{\circ} \mathrm{C}$ and $34.80{ }^{\circ} \mathrm{C}$, respectively. Therefore, the second hypothesis that there is no difference in the temperature rise between the light groups was rejected, because the HI group showed a significant $(P<0.05)$ higher temperature rise in the bleaching process compared with the LI group. Because of the insulating effect of the bleaching material reported by Sulieman et al., the presence of the bleaching gel could reduce the temperature increase in anterior teeth surface dramatically, by $87-96 \%$ [40]. Besides, the cooling effect of simulated pulp microcirculation in the thermal behavior of the dentine also has been proved in dentine pulp complex ex vivo [41]. It might occur the temperature rise in the pulp cavity is far less than the maximum temperature rises of the bleaching agent in this study. The lower limit of the temperature that threatened pulp vitality was $5.5^{\circ} \mathrm{C}$ reported by Zach et al. [42]. Therefore, further studies about intra-pulpal temperature measurements are needed to evaluate the effect of temperature rise on bleaching agents. The use of the LED light containing different intensities in this study evaluated the extent of the temperature rise which is important to study the safe temperature level of the bleaching procedure.

Moreover, changes in enamel and dentin micromorphology may be occurred by the long contact time between the bleaching agent with different concentrations and $\mathrm{pH}$ and teeth surfaces, such as the presence of erosions and/ or porosity [43] and changes in mineral content as well as in surface micro-hardness [43-45]. However, a few studies have focused on the effect of increasing temperature of bleaching agent on tooth enamel and dentin. Furthermore, hydrogen peroxide diffusion and changes in enamel and dentin micromorphology studies are necessary to evaluate the bleaching efficiency and tooth sensitivity caused by increasing temperature.

Despite the limitation of this in vitro study, the effect of photo-thermal acceleration was proved for an in-office bleaching agent without photocatalysts, not only the heat generated by light exposure but also light itself may result in more effective bleaching in tooth bleaching. 
Acknowledgements The authors would like to thank the department of Cariology and Operative Dentistry, Graduate School of Medical and Dental Sciences, Tokyo Medical and Dental University, Tokyo, Japan.

\section{Declarations}

Conflict of interest The authors declare no conflicts of interest.

Open Access This article is licensed under a Creative Commons Attribution 4.0 International License, which permits use, sharing, adaptation, distribution and reproduction in any medium or format, as long as you give appropriate credit to the original author(s) and the source, provide a link to the Creative Commons licence, and indicate if changes were made. The images or other third party material in this article are included in the article's Creative Commons licence, unless indicated otherwise in a credit line to the material. If material is not included in the article's Creative Commons licence and your intended use is not permitted by statutory regulation or exceeds the permitted use, you will need to obtain permission directly from the copyright holder. To view a copy of this licence, visit http://creativecommons.org/licenses/by/4.0/.

\section{References}

1. Alqahtani MQ. Tooth-bleaching procedures and their controversial effects: a literature review. Saudi Dent J. 2014;26:33-46. https://doi.org/10.1016/j.sdentj.2014.02.002.

2. Auschill TM, Hellwig E, Schmidale S, Sculean A, Arweiler NB. Efficacy, side-effects and patients' acceptance of different bleaching techniques (OTC, in-office, at-home). Oper Dent. 2005;30:156-63

3. Tay LY, Kose C, Loguercio AD, Reis A. Assessing the effect of a desensitizing agent used before in-office tooth bleaching. J Am Dent Assoc. 2009;140:1245-51. https://doi.org/10.14219/jada. archive.2009.0047.

4. Perdigão J, Baratieri LN, Arcari GM. Contemporary trends and techniques in tooth whitening: a review. Pract Proced Aesthet Dent. 2004;16:185-92 (quiz 94).

5. Gallagher A, Maggio B, Bowman J, Borden L, Mason S, Felix H. Clinical study to compare two in-office (chairside) whitening systems. J Clin Dent. 2002;13:219-24.

6. de Geus JL, Wambier LM, Kossatz S, Loguercio AD, Reis A. At-home vs in-office bleaching: a systematic review and metaanalysis. Oper Dent. 2016;41:341-56. https://doi.org/10.2341/ 15-287-LIT

7. Seghi RR, Denry I. Effects of external bleaching on indentation and abrasion characteristics of human enamel in vitro. J Dent Res. 1992;71:1340-4. https://doi.org/10.1177/002203459207100 61201.

8. Kwon SR, Wertz PW. Review of the mechanism of tooth whitening. J Esthet Restor Dent. 2015;27:240-57. https://doi.org/10. 1111/jerd.12152.

9. Carey CM. Tooth whitening: what we now know. J Evid Based Dent Pract. 2014;14(Suppl):70-6. https://doi.org/10.1016/j.jebdp. 2014.02.006.

10. Zanin F. Recent advances in dental bleaching with laser and LEDs. Photomed Laser Surg. 2016;34:135-6. https://doi.org/10. 1089/pho.2016.4111.

11. Ito Y, Otsuki M, Tagami J. Effect of $\mathrm{pH}$ conditioners on tooth bleaching. Clin Exp Dent Res. 2019;5:212-8. https://doi.org/10. $1002 /$ cre2.172.

12. Kwon SR, Kurti SR Jr, Oyoyo U, Li Y. Effect of light-activated tooth whitening on color change relative to color of artificially stained teeth. J Esthet Restor Dent. 2015;27(Suppl 1):S10-7. https://doi.org/10.1111/jerd.12142.

13. Féliz-Matos L, Hernández LM, Abreu N. Dental bleaching techniques; hydrogen-carbamide peroxides and light sources for activation, an update. Mini review article. Open Dent J. 2014;8:264-8. https://doi.org/10.2174/1874210601408010264.

14. Kishi A, Otsuki M, Sadr A, Ikeda M, Tagami J. Effect of light units on tooth bleaching with visible-light activating titanium dioxide photocatalyst. Dent Mater J. 2011;30:723-9. https://doi. org/10.4012/dmj.2010-210.

15. Bortolatto JF, Pretel H, Floros MC, Luizzi AC, Dantas AA, Fernandez E, et al. Low concentration $\mathrm{H}(2) \mathrm{O}(2) / \mathrm{TiO} \_N$ in office bleaching: a randomized clinical trial. J Dent Res. 2014;93:66s71s. https://doi.org/10.1177/0022034514537466.

16. Suyama Y, Otsuki M, Ogisu S, Kishikawa R, Tagami J, Ikeda M, et al. Effects of light sources and visible light-activated titanium dioxide photocatalyst on bleaching. Dent Mater J. 2009;28:6939. https://doi.org/10.4012/dmj.28.693.

17. Zhang C, Wang X, Kinoshita J, Zhao B, Toko T, Kimura Y, et al. Effects of KTP laser irradiation, diode laser, and LED on tooth bleaching: a comparative study. Photomed Laser Surg. 2007;25:91-5. https://doi.org/10.1089/pho.2006.2025.

18. Mondelli RF, Soares AF, Pangrazio EG, Wang L, Ishikiriama SK, Bombonatti JF. Evaluation of temperature increase during in-office bleaching. J Appl Oral Sci. 2016;24:136-41. https:// doi.org/10.1590/1678-775720150154.

19. Luk K, Tam L, Hubert M. Effect of light energy on peroxide tooth bleaching. J Am Dent Assoc. 2004;135:194-201. https:// doi.org/10.14219/jada.archive.2004.0151.

20. Klaric E, Rakic M, Marcius M, Ristic M, Sever I, Tarle Z. Optical effects of experimental light-activated bleaching procedures. Photomed Laser Surg. 2014;32:160-7. https://doi.org/10.1089/ pho.2013.3658.

21. Luong MN, Otsuki M, Shimada Y, Ei TZ, Sumi Y, Tagami J. Effect of lights with various wavelengths on bleaching by $30 \%$ hydrogen peroxide. Lasers Med Sci. 2019;34:901-906. https:// doi.org/10.1007/s10103-018-2670-y

22. Klaric E, Rakic M, Sever I, Tarle Z. Temperature rise during experimental light-activated bleaching. Lasers Med Sci. 2015;30:567-76. https://doi.org/10.1007/s10103-013-1366-6.

23. Usumez A, Ozturk N. Temperature increase during resin cement polymerization under a ceramic restoration: effect of type of curing unit. Int J Prosthodont. 2004;17:200-4.

24. Kyaw KY, Otsuki M, Segarra MS, Tagami J. Effect of sodium fluoride pretreatment on the efficacy of an in-office bleaching agent: an in vitro study. Clin Exp Dent Res. 2018;4:113-8. https://doi.org/10.1002/cre2.113.

25. Nematianaraki S, Fekrazad R, Naghibi N, Kalhori KA, Junior $\mathrm{AB}$. Effects of the bleaching procedures on enamel microhardness: plasma Arc and diode laser comparison. Laser Ther. 2015;24:173-7. https://doi.org/10.5978/islsm.15-OR-10.

26. Kossatz S, Dalanhol AP, Cunha T, Loguercio A, Reis A. Effect of light activation on tooth sensitivity after in-office bleaching. Oper Dent. 2011;36:251-7. https://doi.org/10.2341/10-289-c.

27. Torres CR, Souza CS, Borges AB, Huhtala MF, Caneppele TM. Influence of concentration and activation on hydrogen peroxide diffusion through dental tissues in vitro. Sci World J. 2013;2013:193241. https://doi.org/10.1155/2013/193241.

28. Buchalla W, Attin T. External bleaching therapy with activation by heat, light or laser-a systematic review. Dent Mater. 2007;23:586-96. https://doi.org/10.1016/j.dental.2006.03.018.

29. Maran BM, Burey A, de Paris MT, Loguercio AD, Reis A. Inoffice dental bleaching with light vs. without light: a systematic 
review and meta-analysis. J Dent. 2018;70:1-13. https://doi.org/ 10.1016/j.jdent.2017.11.007.

30. Polydorou O, Hellwig E, Hahn P. The efficacy of three different in-office bleaching systems and their effect on enamel microhardness. Oper Dent. 2008;33:579-86. https://doi.org/10.2341/07-148.

31. Mellberg JR. Hard-tissue substrates for evaluation of cariogenic and anti-cariogenic activity in situ. J Dent Res. 1992;71:913-9. https://doi.org/10.1177/002203459207100s25.

32. Hartmann R, Müller F. Clinical studies on the appearance of natural anterior teeth in young and old adults. Gerodontology. 2004;21:10-6. https://doi.org/10.1111/j.1741-2358.2004.00009.x.

33. Camargo MA, Marques MM, de Cara AA. Morphological analysis of human and bovine dentine by scanning electron microscope investigation. Arch Oral Biol. 2008;53:105-8. https://doi.org/10. 1016/j.archoralbio.2007.09.005.

34. Laurance-Young P, Bozec L, Gracia L, Rees G, Lippert F, Lynch $\mathrm{RJ}$, et al. A review of the structure of human and bovine dental hard tissues and their physicochemical behaviour in relation to erosive challenge and remineralisation. J Dent. 2011;39:266-72. https://doi.org/10.1016/j.jdent.2011.01.008.

35. Trentino AC, Soares AF, Duarte MA, Ishikiriama SK, Mondelli RF. Evaluation of $\mathrm{pH}$ levels and surface roughness after bleaching and abrasion tests of eight commercial products. Photomed Laser Surg. 2015;33:372-7. https://doi.org/10.1089/pho.2014.3869.

36. Ruyter IE, Nilner K, Moller B. Color stability of dental composite resin materials for crown and bridge veneers. Dent Mater. 1987;3:246-51. https://doi.org/10.1016/s0109-5641(87)80081-7.

37. Tung FF, Goldstein GR, Jang S, Hittelman E. The repeatability of an intraoral dental colorimeter. J Prosthet Dent. 2002;88:585-90. https://doi.org/10.1067/mpr.2002.129803.

38. De Moor RJ, Delmé KI. Laser-assisted cavity preparation and adhesion to erbium-lased tooth structure: part 1. Laser-assisted cavity preparation. J Adhes Dent. 2009;11:427-38. https://doi. org/10.3290/j.jad.a18136.
39. Eldeniz AU, Usumez A, Usumez S, Ozturk N. Pulpal temperature rise during light-activated bleaching. J Biomed Mater Res B Appl Biomater. 2005;72:254-9. https://doi.org/10.1002/jbm.b.30144.

40. Sulieman M, Addy M, Rees JS. Surface and intra-pulpal temperature rises during tooth bleaching: an in vitro study. $\mathrm{Br}$ Dent J. 2005;199:37-40. https://doi.org/10.1038/sj.bdj.48125 58.

41. Kodonas K, Gogos C, Tziafas D. Effect of simulated pulpal microcirculation on intrapulpal temperature changes following application of heat on tooth surfaces. Int Endod J. 2009;42:247-52. https://doi.org/10.1111/j.1365-2591.2008.01508.x.

42. Zach L, Cohen G. Pulp response to externally applied heat. Oral Surg Oral Med Oral Pathol. 1965;19:515-30. https://doi.org/10. 1016/0030-4220(65)90015-0.

43. Nascimento WC, Gomes Ydo S, Alexandrino LD, Costi HT, Silva JO Jr, Silva CM. Influence of fluoride concentration and $\mathrm{pH}$ Value of 35\% hydrogen peroxide on the hardness, roughness and morphology of bovine enamel. J Contemp Dent Pract. 2014;15:392-8. https://doi.org/10.5005/jp-journals-10024-1550.

44. Parreiras SO, Vianna P, Kossatz S, Loguercio AD, Reis A. Effects of light activated in-office bleaching on permeability, microhardness, and mineral content of enamel. Oper Dent. 2014;39:E22530. https://doi.org/10.2341/13-031-1.

45. Klaric E, Rakic M, Sever I, Milat O, Par M, Tarle Z. Enamel and dentin microhardness and chemical composition after experimental light-activated bleaching. Oper Dent. 2015;40:E132-41. https://doi.org/10.2341/14-148-1.

Publisher's Note Springer Nature remains neutral with regard to jurisdictional claims in published maps and institutional affiliations. 